\title{
Analysis on the Propagation Influence and Effect of Film and TV Media on China's Music Culture-take "The Voice of China” as the Example
}

\author{
Hui Chen \\ Xi'an Shiyou University, Xi'an Shaanxi, 710065, China
}

Keywords: The Voice of China; cultural atmosphere; media operation; musical connotation

\begin{abstract}
Chinese singing talent shows have experienced eight years of ups and downs with the development of China's film and television media, including high-profile "Super Girl" which was popular in whole China, and various types of imitation TV programs such as "Happy Girls" "Happy Boys", in addition to the "Chinese Idol" and "China's Got Talent" which imitate foreign singing talents from the beginning of 2005. These singing talent shows have fallen into a development bottleneck while screening excellent folk singers and providing grand musical banquet for audience.
\end{abstract}

\section{Introduction}

With the launch of "The Voice of China," a wide range of "earthquakes" occurred after Chinese singing talent show programs have experienced the process of initial explosion, early imitation, and mid-term silence, which inspired the industry insiders with enthusiasm A new round of discussion was initiated in academic circle after great concern of Chinese talent show program. "The Voice of China" is a feast for music appreciation and enjoyment, as well as the result of cultural orientation and collision. While Chinese audiences are eager for novelty programs close to daily life, "The Voice of China" has emerged at the right time and become the leader of Chinese signing talent show program.

\section{New features and influence of current TV media}

\subsection{New pattern of TV media is generated in the macro environment of cultural transformation} in the new era

With the accelerating process of economic integration, and obvious trend of global unification, particularly cultural exchange has passed beyond national boundaries and existed in the cultural fields of various countries as a cultural unity. Economic globalization in the new era has brought about exchanges in different cultural circles. The intervention of mighty economies has brought about cultural invasion and engulfment. What follows is the exchange and communication of film and television media culture and concepts. There exists no unified or single cultural exchange. The collision of various concepts and ideas is the theme of cultural exchange. Cultural globalization has made the diversified cultures in different geographical locations and temporal locations united into the cultural richness of a certain space, thus greatly increasing the concentration of cultural diversity. The content and form of the film and television media have enhanced their influence [1] after getting rid of the limitation of previous TV programs by drawing reference from excellent elements in various fields. Film and television programs such as “Mr. Zhou Live Show” and "Tonight 80's Talk Show" have incorporated foreign popular elements and gained widespread popularity in China.

Under the influence of China's reform and opening up environment, tremendous changes have happened in China's political, economic, and cultural fields, which also resulted in dramatic changes of China's social ideology. The unified and centralized cultural ideas advocated traditionally have been challenged and replaced by multicultural structure integrating collective culture, cutting-edge culture, and trending culture. People's aesthetics and cognitions have changed significantly. Popular 
culture and trendy ideas are flooded in every social classes, and film and television media have to fill a variety of cultures into own "body" for its own survival despite of contradictory and vague properties in the culture.

\subsection{Successful TV media operation can influence the guidance of public opinion to a great degree}

With the increasingly obvious political influence of TV media, a lot of TV media have promoted universal value with their own works. As the leader in film and TV media field, American Hollywood blockbuster has become important cultural symbol which enjoys widespread popularity among the public without barriers in the sphere of adverse influence. America has succeeded in spiritual and cultural invasion through Hollywood and shaped American hero image and the splendid American dream around the world. The determination of this spiritual symbol has wakened up the country's film and television media to realize the potential influence of the film and television media on social spirit and image. "Superman", "Star Trek" and other works have untiringly improved American international hero image, and conquered the world audience through other film and television techniques, penetrated deeply into the hearts of the audience, promoted American social values and American-style human rights views, and then implied US superiority by utilizing a wide range of inherent image.

The main purpose of the film and television media is to influence people's thinking and values, so as to form the overall thinking consciousness conducive to social development. Despite of impure purpose of Hollywood in the United States, its operating means are worth our reference. People have lost their respect for heaven and earth with the development of society. Technology which can facilitate people's life but cannot allow people to produce valuable exploration for life. With the abundant materials in people's life, impoverishment of spiritual exploration follows. People are needing the sustenance for their soul and spirit, release of emotions and spiritual support. Film and television media can provide a bright color for spiritual life so that people can find spiritual relief. The great virtue of the hero for love in Titanic is carried with the most glittering part of human nature and perception. Therefore, the success of Titanic is no accident.

\section{Analyze the influence of film and TV media operation on musical culture with "The Voice of China" as the example}

\subsection{The current operation status of "The Voice of China"}

"The Voice of China" as a large-scale professional music commentary program created by Zhejiang Satellite TV in prime time has received widespread attention at the beginning of the broadcast. Its audience rating and click rate hit record high and became the backbone of Zhejiang Satellite TV. "The Voice of China" based on "The Voice of Holland" has formed its own brand with great influence through processing among Chinese film and television media. The program gathered Na Ying, Liu Huan, Yang Kun, and Yu Chengqing as top four masters of Chinese music circle on a stage to act as instructors of students from different places of China. The unique setting of voice-listening and turning in the program has highlighted the purpose of "finding Chinese music superstars". With no splendid stage effects, no exquisite situation setting, there is only a battlefield of voices in "The Voice of China" [1]. A person who wants to laugh the last laugh must obtain the instructor's recognition with own singing power The purpose is to find Chinese folk music talents so as to transport a batch of fresh and high-quality musical blood into Chinese musical circle.

As the show proceeds, the program has established a successful business operation model. Although the market and the audience changed repeatedly, "The Voice of China " has broken through the barriers of the film and television media several times, and brought huge benefits to all participating parties. The excellent commercial operation level has caused negative influence and query. However, business interests and the spiritual values of an entertaining talent show will always be the focus of debates. The enhancement of its commercial value has not affected the main purpose 
of the program. It has created a win-win situation by making use of various cooperation and exchange. "The Voice of China" has provided a good platform for the further dissemination of music culture through rational use of film and television media operating means. It retains the original intention of the program while guaranteeing its own interests and development.

\subsection{Operation concept of "The Voice of China” and its influence on China's film and TV media}

Adapting The Voice of Holland to "The Voice of China" embodies the characteristics of cultural integrated communication under different cultural backgrounds and living environments. "The Voice of China" has reasonably used the characteristics of cultural communication globalization, transformed foreign popular cultural media phenomenon into a Chinese-style media, and generated huge chemical reaction of advertising, entertainment programs, competitive awareness and other compounds, so as to exert great influence. There are numerous channels for film and television media communication. The crowd, the general public, and the media itself are the directions for expanding their influence. However, as a new pattern media emerging in the new era, international communication has the advantages that cannot be replaced by other communication modes. In a word, "Absorbing others experiences and improving ourselves". "The Voice of China" with "The Voice of Holland" as the blueprint has combined the current condition of China's film and television media, packaged and integrated various customs, beliefs, and public opinions in different regions through media methods such as the collision of Chinese and Western media and culture under the premise of not reducing the original program intention, The act of introducing foreign media programs, and combining with the national conditions has brought about huge international effect. China's film and television media has started paying attention to the media model of combining the foreign media operating mode with China's national conditions.

Outstanding brand protection awareness is also an important factor for the success of the program. The program brand is the core value, and "The Voice of China" has penetrated the aim of "sound dominating everything" deeply and used it as a powerful means of self-development to attract attention and enhance the taste of the program through excellent brand strategies. As the sole judgement criterion, musical strength makes it clear at a glance and increases public credibility after removing the complexity of redundant technical judgments. People are willing to pay attention to the progress of the program. The means of making hard things simple makes China's film and television media realize that music talent show program can also be operated in this way. This has accelerated the development and popularization of music.

\section{3 “The Voice of China” has promoted the development of China's music culture to a new peak by driving music media implementation chain}

The mode of guest invitation of "The Voice of China" is greatly different from the past. The guest mentors with long-term cooperation with the program have jointed created an independent music brand industry chain, enhanced the influence of the mass-election stars, and expanded the influence of the Chinese music circle, broadened the effect scope of Chinese music culture. "The Voice of China" owns the player's commercial performance rights, and at the same time, mentors directly participate in a series of concerts, trainings, and group performances related to the music production industry chain. Meanwhile, mentors use their own musical strength and music resources to perfect the industry chain. The mutually beneficial participation and operation model is another attempt of the film and television media. Getting the public actively participated in the interaction, "The Voice of China” program which involves the mutual selection between mentors and players is also audiences' judgement of the players. Each player's growth process and tough experience can be seen clearly, and the multi-mentor selection way can also reduce the possibility of black-box operations to a certain extent. The whole program gets closer to the audience and becomes more attractive. As mentioned above, we can see that people pay more attention to the quality of music and focus less on other aspects, which is more conducive to penetrating positive energy of the music culture into people's mind.

By introducing a series of player packaging methods and sending some outstanding trainees 
directly to the front line of the show, the program has practiced their singing ability in actual combat. This original ecological promotion mode has attracted widespread attention. The music performance, skills, means and culture have also been discussed by the people with great audience participation. In addition to the sharp comments by mentors, previous musical terms in the ivory tower are well known to the general public, and the music culture has been further promoted through "The Voice of China".

\section{Far-reaching influence and enlightenment effect of film and TV media on Chinese music}

\subsection{Film and TV media is attracting more and more people to focus on China's music depending on its entertainment}

Elite culture with deep connotation is difficult to be accepted by the masses. To get rid of its minority influence, it began to gradually shift to the realistic and intuitive mass culture. The cultural concept has been gradually replaced by "superficial" from the previous "profound". In this way, the entertainment compositions of culture gradually increase, especially in music culture. The music is produced for the purpose of people's entertainment. In the process of music development, the musicians appreciate themselves too much. Music culture has detached from the masses to become "academic products". People acclaim after seeing the "cultural mountains". With the current trend of cultural popularization, music is active in major media with its influence over a century. Various types of music shows have emerged endlessly. Various music awards are dazzling people's eyes. The music circle has become an entertainment industry. People can get access the elegant thing far away from them before. Chinese music has displayed its influence in various fields [1], and "The Voice of China" is the most typical example of the organic combination of contemporary music culture and film and television media. It can be seen from the above that a culture rooted in the masses can be truly enduring.

\subsection{Film and TV media excavating the inherent charm of music and its innovative operating means have expanded its influence in different domains}

The influence of music has increased year by year with various media dissemination. Even some seemingly irrelevant areas in the past have been affected by music. There exist a classic case of "besieged on all sides" in ancient China that used music in psychological warfare. In the "World War II”, similar methods were also used occasionally. People in modern society even the ancient time have realized that music has a psychological impact. The influence of music in the film and television dramas is also obvious. Many musical works from generation to generation are from homonymous films and television dramas. Coverage of musical contents and the setting-off of the characters' feelings are necessary means in film and television drama shooting. Advertising songs and endorsement theme songs are active in recent years. The theme song of Yonghe King has become a topic of teasing conversation among the 80s generation. The Japanese fruit juice endorsement song "Love Song" has been well known by music lovers at home and abroad as the representative work of GReeeeN. Music has already become the most popular culture with the largest application and acceptance under the current cultural impact background after breaking through its traditional influence range. At the same time, music without regionalism has evolved into an art form integrating various manifestation and creation forms. Film and television media workers should further expand their potential influence and sphere of influence, so as to get music culture penetrated into every corner of life.

\section{Summary}

Successful operation of the film and television media has transformed Chinese music culture from "elite culture" to a "mass culture" so that it is well-known to the people. At the same time, the film and television media have also made profits for itself. The "win-win" operation has greatly improved 
the enthusiasm of cultural communication and development. So, it deserves reference for other cultural fields.

\section{References}

[1] Xu Xiaomin. Discussion on the development of film and TV music, China's Foreign Trade; 16th issue, 2010.

[2] Peng Simin. Importance of film and TV music and its practical application, Charming China; 4th issue, 2009.

[3] Zhang Yi. Discussion on the artistic value of film and TV music, Movie Review; 1st issue, 2007. 